\title{
Toward a taxonomy of micro and small manufacturing enterprises
}

\author{
Budhi Sholeh Wibowo ${ }^{a^{*}}$, Nur Aini Masruraha ${ }^{a}$ Yulinda Uswatun Kasanaha ${ }^{a}$, Fitri Trapsilawati ${ }^{a}$, \\ Subagyo $^{\mathrm{a}}$, Muhammad Adha Ilhami ${ }^{\mathrm{b}}$ \\ ${ }^{a}$ Department of Mechanical and Industrial Engineering, Universitas Gadjah Mada, Jl. Grafika 2 Yogyakarta, 55281, Indonesia \\ ${ }^{b}$ Universitas Sultan Ageng Tirtayasa, Banten, 42124, Indonesia
}

Article history:

Received: 13 August 2019 / Received in revised form: 3 December 2019 / Accepted: 3 December 2019

\begin{abstract}
The business sustainability of micro and small manufacturing enterprises (M-MSEs) are substantial to drive productivity and employment rate in many developing countries. However, due to various limitations, these enterprises are struggling to develop themselves into larger enterprises. For this reason, the government of Indonesia is enthused to provide technical and managerial supports for these M-MSEs. This study aims to provide an objective taxonomy of Indonesian M-MSEs as a guidance for the authorities to deliver the appropriate supports. The taxonomy was developed based on the survey to 735 M-MSEs in the Yogyakarta area. By using cluster analysis, we found that the M-MSEs can be classified into four distinct groups. Each group has its development strategies, ranging from adopting lean philosophy to instituting relationship marketing. This taxonomy provides useful directions for the authorities to support the development of M-MSEs in Yogyakarta and also serves as part of a broader effort to construct M-MSEs taxonomy in Indonesia.
\end{abstract}

Keywords: entrepreneurship, micro-business; manufacturing; cluster analysis; strategic management.

\section{Introduction}

Micro and Small Enterprises (MSEs) have been acknowledged as the drivers of economic growth and job creation in many countries. Even though MSEs are mainly found in rural areas, but their existence dominates the majority of businesses in both developing and developed countries. For example, in Indonesia, 99.9\% of local enterprises are MSEs [1]. Despite only having 1-19 workers per business [2], these enterprises absorb $93 \%$ of total labor in Indonesia and generate more than 43 percent of Indonesia's GDP [2]. With the massive labor absorption, MSEs have helped to provide jobs and basic income to many households in Indonesia. They are also found to be reliable during a monetary crisis since the majority of the enterprises are not dependent on external funding [3].

Amongst various sectors of MSEs in Indonesia, the manufacturing sector is found to be the sector with the highest productivity [1]. While the annual productivity of MSEs in Indonesia was around USD 2,500 per labor, the productivity of micro and small manufacturing enterprises (M-MSEs) was found to be USD 8,000 per labor or three times higher than the average MSEs [1]. Moreover, the growth rate of these enterprises also reaches 5.7 percent per year, surpassing the growth of their larger counterparts, which only attains 4.3 percent per year [1]. By absorbing more than 8.7 million workers, these enterprises also have become the primary and secondary source of income for many households in Indonesia

* Corresponding author.

Email: budhi.sholehwibowo@ugm.ac.id
[2]. In 2015, they generated more than 570 trillion IDR or about 6.3 percent of total GDP in Indonesia [1]. Therefore, based on these facts, the successful development of M-MSEs will have a significant impact to fight unemployment and alleviate poverty in Indonesia.

Due to many benefits of local M-MSEs for the economy, there is increasing attention from the Government of Indonesia to assist these enterprises into larger companies. Evidence has suggested that the development of appropriate development strategies for manufacturing enterprises are critical to support their competitiveness and business performance [4]. However, since the number of M-MSEs in Indonesia are enormous, it will not be efficient for the government to provide unique supports for each enterprise. From a public policy perspective, it is more effective for the government to supports a group of enterprises with similar characteristics instead of dealing with them one by one.

This study aims to provide an empirical-based taxonomy of Indonesian M-MSEs as guidance for the authority to deliver the required supports for these enterprises. Specifically, this study has two objectives: (1) to identify the significant characteristics of Indonesian M-MSEs and (2) to examine the appropriate strategy to unlock the potentials of M-MSEs in Indonesia. The study was conducted based on the samples of 735 Indonesian M-MSEs in the Yogyakarta region. Yogyakarta is a province in the center-south of Java, the most inhabited island in Indonesia. The population in Yogyakarta is about one million people, with an average income of USD 2.052 per capita [5]. The M-MSEs in this region are particularly diverse, both in the type of sectors and level of development. Thus, the study of M-MSEs in 
Yogyakarta can provide useful insights for policymakers as part of the greater effort to the development of the taxonomy of M-MSEs in Indonesia and in developing countries, in more general context.

The remainder of this paper is organized as follows. In Section 2, we provide literature reviews related to the study. In Section 3, we describe the data and methods used in this study. Section 4 is dedicated to the results and discussions. Finally, we provide conclusions and managerial implications of this study in Section 5.

\section{Literature Reviews}

Numerous studies in the literature have proposed the taxonomy of strategies for enterprises based on a cluster analysis. For instance, [6] used Porter's generic strategies to classify group membership and organizational performance of large enterprises. They found that an organization that adopts at least one of generic strategies tend to have outstanding performance. The study in [7] used cluster analysis to classify founder motivation in starting up a business. The taxonomy was then used to predict the growth performance of the business. [8] employed cluster analysis to large American manufacturers. They found that American manufacturers can be classified into three groups, that is caretakers, marketers, and innovators. Out of all different types of classification, the taxonomy from [8] seems to gain much attention from scholars and practitioners. Their taxonomy has been frequently cited and used in the operations management study as a benchmark. More recently, [9] also proposed the use of cluster analysis to develop a taxonomy of strategy for Industry 4.0 implementation in Indonesia.

Despite the effort to provide a generic taxonomy for all kind of enterprises, many scholars have argued that different size of companies faces different challenges and environment [10], [11]. Therefore, several studies have attempted to develop unique taxonomies for different sizes of enterprises, especially for small and medium enterprises (SMEs). For example, [12] developed a taxonomy for Australian SMEs based on a longitudinal survey. He identified that there are three different growth development pathways for the SMEs in Australia: high, moderate, and low growth. These paths distinguish the pace of SMEs' development to a larger business. [11] also investigated the taxonomy of high performing SMEs in Singapore based cost, delivery, efficiency, and quality. They identified significant differences between the clusters based on the operational posture, financial performance, and the kinds of improvement programs. Moreover, [13] constructed the taxonomy of 186 M-MSEs in Sweden based on six dimensions: cost, complexity, marketing, innovation, technology, and customer. The study identified that there are six clusters of Swedish M-MSEs, namely: Ikeas, Technocrats, Conservatives, Marketeers, Craftsmen, and Nomads.

Nevertheless, the taxonomies, as mentioned earlier, are mostly developed based on the samples of enterprises in developed countries. The SMEs in developing countries have been known to have distinct characteristics and different growth path compared to the SMEs in developed countries [14]. It is also important to note that, in most developing countries, M-MSEs in rural areas constitute a higher share of business than those in urban areas [10]. Therefore, with a large share of households in rural areas depending on their income on MSEs, a study on this area should provide a better insight to support economic development in the developing countries.

An effort to provide a sample of SMEs' characteristics in a developing country is performed by [15]. Their study proposed a practical method for classifying Mexican SMEs based on levels of knowledge related to their specific problems that dominate the company's operations. They found that the level of knowledge does not correlate to the number of workforce and sales performance of SMEs in Mexico. Likewise, [16] also performed an empirical study on three strategic Industrial sectors in Nigeria. They found that SMEs are significant drivers to the economic development in Nigeria. The study confirms that SMEs do not only contribute to job creation but also improve the standard of livings and reduce the poverty of many people in Nigeria.

Our research contributes by providing a new sample to the characteristics of M-MSEs in developing countries, which is currently underrepresented in the literature. In this study, we examined M-MSEs in Indonesia as a case study. Indonesia is a developing country which also the largest economy in SouthEast Asia. Nonetheless, their GDP per capita still ranks below the world average, and many of the population are still living in poverty [17]. As a dominant constituent in the country, the development of M-MSEs should plays a significant role in improving nation-wide productivity and employment in Indonesia.

\section{Data and Methods}

The study was based on the business performance of 735 Indonesian M-MSEs in Yogyakarta province. The data was acquired from a survey performed by the Regional Office of Industry and Trade Department (Disperindag) in 2018. It contains a set of M-MSEs' business characteristics such as the total workforce, monthly revenue, gross margin, and the working capital.

The participants for the surveys came from a wide range of industrial sectors ranging from textile and apparel, wood and furniture, to metal and engineering. The characteristics of the enterprises participating in the survey are summarized in Table 1. Due to historical reasons, most M-MSEs in Yogyakarta are co-located in certain areas. This condition makes the M-MSEs in Yogyakarta often work as a group, which is called the industrial center (Sentra Industri). This center sets many similar manufacturers in the same area to collegially work for cultivating their advantage over other competitors in the market.

Table 1. Statistics of the respondents

\begin{tabular}{lccc}
\hline Sectors & $\begin{array}{c}\text { Number of } \\
\text { Industrial Centers }\end{array}$ & $\begin{array}{c}\text { Number of } \\
\text { Enterprises }\end{array}$ & Percent \\
\hline Construction & 3 & 320 & $44 \%$ \\
Food and Beverage & 4 & 128 & $17 \%$ \\
Metal and Engineering & 1 & 11 & $1 \%$ \\
Textiles and Apparel & 3 & 57 & $8 \%$ \\
Wood and Furniture & 3 & 219 & $30 \%$ \\
\hline Total & 14 & 735 & $100 \%$ \\
\hline
\end{tabular}


To develop an empirical-based taxonomy of the M-MSEs in Yogyakarta, we employed a cluster analysis based on the business performance of the enterprises. Cluster analysis aims to discover the underlying structure amongst individuals observed in the data based on the characteristics they possess. The analysis systematically segments the observations into clusters in a way that the observations in the same cluster are more similar to one another compared to the observations in other clusters. In other words, the objective of cluster analysis is to maximize the homogeneity of individuals within the clusters while also maximizing the heterogeneity between the clusters.

The first step to perform cluster analysis is to determine the similarity measure between the individuals/objects in the study. The similarity measure should embody the degree of correspondence among objects through all the characteristics used in the analysis. In this study, the similarity between the objects is measured on the basis of Euclidean distance (proximity). Hence if there are $p$ variables, the distance between two objects can be measured as follows:

$$
d_{i j}=\sqrt{\sum_{k=1}^{p}\left(x_{i k}-y_{j k}\right)^{2}}
$$

where $d_{i j}$ is the distance between object $i$ and object $j$, and $x_{i k}$ is the value of dimension $k$ for object $i$ while $y_{j k}$ is the value of dimension $k$ for object $j$. Based on this measure, if the clustering process is effective, the individuals within the clusters will be close together, and different clusters will be far apart when plotted geometrically. However, since the variables may have different scales, it is necessary to standardize the values so that the range for each variable are equal when compared directly. The standardization of the unit measurement is necessary to avoid weighting differences between variables due to the differences in the value ranges. The standardization of unit measurement was performed based on the following equation:

$$
z_{i k}=\frac{x_{i k}-\mu_{x k}}{\sigma_{x k}}
$$

where $z_{i k}$ is the standardized value of variable $k$ for object $i, x_{i k}$ is the value of variable $k$ for object $i, \mu_{x k}$ is the mean, and $\sigma_{x k}$ is the standard deviation of variable $k$.

We employed a hierarchical clustering procedure to form a number of clusters from the observations. In this method, the first step is to identify the two closest individuals and combine them into a cluster. We then repeat this process to find the next closest pairs of individuals until no remaining individuals left.

One of the major challenges in using cluster analysis is to determine the optimal number of clusters. In this study, we used the average Silhouette score as the criterion. Silhouette score is a degree which measures how similar an object is to its cluster. The score ranges from -1 to +1 , where a high value implies that the objects have a high similarity to its cluster and low similarity to the other clusters. Compared to elbow method which often provide subjective result, Silhouette score can provide unambiguous optimal number of clusters [18].

Let us define $a(i)$ as the mean distance of object $(i)$ to all other objects in the same clusters. We also define $b(i)$ as the mean distance of the object $(i)$ as to all other objects in the neighboring clusters. Therefore, we can define the Silhouette score $s(i)$ as the following:

$$
s(i)=\frac{b(i)-a(i)}{\max \{a(i), b(i)\}}
$$

The mean of $s(i)$ is a measure of how cohesive all the objects in the cluster are. Thus, the mean of all the objects in the dataset is a measure of how appropriately the data have been clustered.

In this study, we used software Orange version 3.1 to implement the clustering algorithm. Ward's method was selected as the algorithm to define the similarity between multiple-member clusters in the clustering process.

The research framework for this study is shown in Fig. 1. The research started with the data collection and cleaning procedures as an input to the cluster analysis. The cluster analysis was then employed to develop the natural taxonomy of the M-MSEs in Yogyakarta based on the four business measures retrieved from the surveys. The derived taxonomy is used as a basis to identify the main characteristics for each cluster and also to develop the appropriate strategies for the enterprises belong to the cluster. The discussions of the findings from the analysis are provided in the following section.

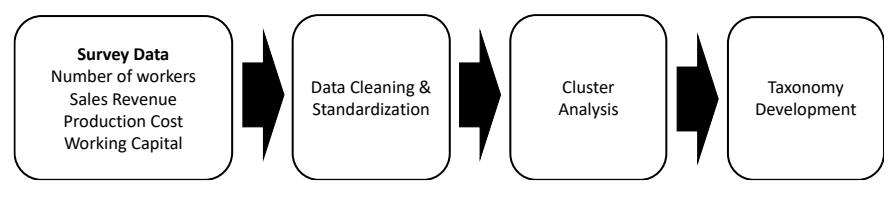

Fig. 1. Research framework

\section{Results and Discussion}

This study used hierarchical clustering to develop the taxonomy of M-MSEs in Yogyakarta. Four variables were used as inputs for the analysis, i.e., the number of workers, working capital, revenue, and gross margin performance. From the data, we found that most of the M-MSEs' performance in Yogyakarta are relatively similar. Consequently, treating the individual enterprise as the unit of analysis can result in meaningless taxonomy. In order to create a well-separated group, cluster analysis requires sufficient variability between the individuals to identify the underlying pattern and generate a useful taxonomy. Thus, to address this problem, we grouped the individual enterprises into their corresponding industrial centers, and treated the center itself as the unit of analysis. The statistics of the industrial center are summarized and presented in Table 2.

The optimal number of clusters was determined by the silhouette score. By comparing the silhouette score for a various number of clusters, we found that the industrial centers in Yogyakarta can be optimally represented with four clusters (see Fig. 2). This result means that by using four clusters, the similarity between the industrial centers in the same group can be maximized while maintaining the heterogeneity across different clusters.

The final taxonomy of industrial centers in Yogyakarta is depicted in Fig. 3. The figure depicts the relative position for each cluster based on the working capital and the total revenue. 
The result suggests that different sectors can be found within the same cluster. This means that each sector can adopt different strategies instead of adhering to a single uniform strategy. The common characteristics of the enterprises in each cluster were used as a basis to determine the appropriate development strategy for the enterprises. The characteristics of the clusters, along with the managerial implications, are discussed in the following subsections.

Table 2. Performance of the Industrial Centers

\begin{tabular}{|c|c|c|c|c|c|c|}
\hline Sectors & $\begin{array}{l}\text { Industrial } \\
\text { Centers }\end{array}$ & $\begin{array}{c}\text { Number } \\
\text { of M-MSEs }\end{array}$ & $\begin{array}{l}\text { Avg. Number } \\
\text { Of Workers }\end{array}$ & $\begin{array}{c}\text { Avg. Revenue } \\
\text { (thousands IDR) }\end{array}$ & $\begin{array}{c}\text { Avg. Working } \\
\text { Capital (thousands } \\
\text { IDR) }\end{array}$ & $\begin{array}{l}\text { Avg. } \\
\text { Gross } \\
\text { Margin }\end{array}$ \\
\hline \multirow{3}{*}{ Construction } & Sand Bricks & 20 & 5.40 & 37,748 & 15,209 & $324 \%$ \\
\hline & Roofing I & 121 & 2.02 & 10,474 & 22,010 & $286 \%$ \\
\hline & Roofing II & 179 & 2.25 & 9,603 & 13,408 & $364 \%$ \\
\hline \multirow{4}{*}{ Food and Beverage } & Fried Chicken & 24 & 2.88 & 35,905 & 2,852 & $78 \%$ \\
\hline & Traditional Foods & 12 & 2.33 & 7,297 & 12,134 & $240 \%$ \\
\hline & Soy and Tofu & 66 & 1.97 & 7,220 & 2,667 & $67 \%$ \\
\hline & Herbal drinks & 26 & 1.77 & 3,177 & 414 & $224 \%$ \\
\hline \multirow[t]{2}{*}{ Metal and Engineering } & Brass Souvenirs & 11 & 3.09 & 27,160 & 3,500 & $328 \%$ \\
\hline & Clothes Convection & 30 & 5.40 & 43,518 & 5,546 & $194 \%$ \\
\hline \multirow[t]{3}{*}{ Textiles and Apparel } & Batik Souvenirs & 18 & 1.72 & 17,221 & 3,532 & $190 \%$ \\
\hline & Batik Clothing & 9 & 1.00 & 671 & 418 & $76 \%$ \\
\hline & Bamboo Souvenirs & 20 & 2.55 & 21,107 & 527 & $460 \%$ \\
\hline \multirow[t]{2}{*}{ Wood and Furniture } & Bamboo Furniture & 37 & 1.76 & 2,576 & 266 & $112 \%$ \\
\hline & Woven Bamboo & 162 & 1.03 & 864 & 2,047 & $189 \%$ \\
\hline
\end{tabular}

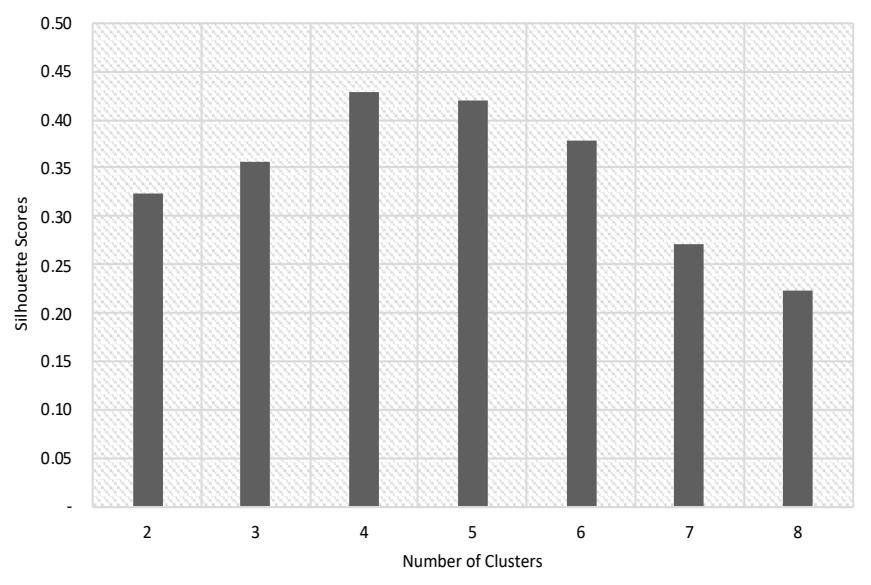

Fig. 2. Silhouette score for a various number of clusters

\subsection{Cluster A: High Gross Margin, Mediocre Revenue}

Table 3 summarizes the characteristics of each cluster. From the table, we can see that Cluster A typically has a high margin, a low working capital, and a mediocre revenue. The industrial centers that belong to this cluster are the brass and the bamboo industry. With those characteristics, the M-MSEs in Cluster A has many potentials to grow. However, their sales performance is found to be mediocre, suggesting that the M-MSEs in Cluster A are struggling to grow their market and increase sales.

From the interviews with the company owners in Cluster A, we discovered that the problem was not because of the limited market, but more often due to the inadequate production capacity so that they cannot accept larger orders from their customers. This limitation comes from the fact that their capacity is mostly dependent on the availability of skilled labors. Currently, enterprises only have 2-3 employees, and they found it difficult to attract new employees to work with them. Even though the margin in the brass and the bamboo market is relatively high, but the production process often requires specific skills and physical labor. Therefore, the workplace often becomes an unattractive option for many job seekers.

Based on the characteristics, we determined that the appropriate strategy for this cluster is to procure mechanical tools or machinery equipment. Mechanical tools can help them to increase production capacity without depending too much on human labor. The enterprises may also work with a university to provide technical support in the design and procurement of the right equipment. With the aid of machinery, enterprises can increase their capacity and serve a higher number of orders. [10] suggested that small enterprises which are continuously seeking to expand and to add their labor force often have high growth potentials. Thus, helping these enterprises to grow would also help many people out of poverty.

\subsection{Cluster B: High Revenue, Low Margin}

Cluster B is characterized by a high revenue and a high workforce, but with a low-profit-margin compared to other clusters. This cluster represents a labor-intensive industry and commodity sectors such as foods and clothes. Since this type of sector typically does not require high skills or high technology, there are also low barriers for others to enter the market. Consequently, the market becomes more efficient; the margin is sinking and lowering their business profitability. Under such a competitive environment, the M-MSEs in this cluster should change the way to look at profit. According to [19], the only 
way to make a profit and survive in this kind of environment is to reduce the operational cost.

One way for enterprises to reduce the operational cost is by adopting a lean philosophy in their organization. Lean is the identification and elimination of non-value added processes or "waste." The goal of a lean organization is to create a smooth and high-quality process that can produce finished products and provide service to satisfy customers' demand with no waste. Since many of the M-MSEs depend on the external parties for knowledge and technical support, the government can assist the adoption of lean philosophy by providing essential training and workshops. By implementing lean management, enterprises could reduce their operational costs and increase their profit margin for the sake of business sustainability.

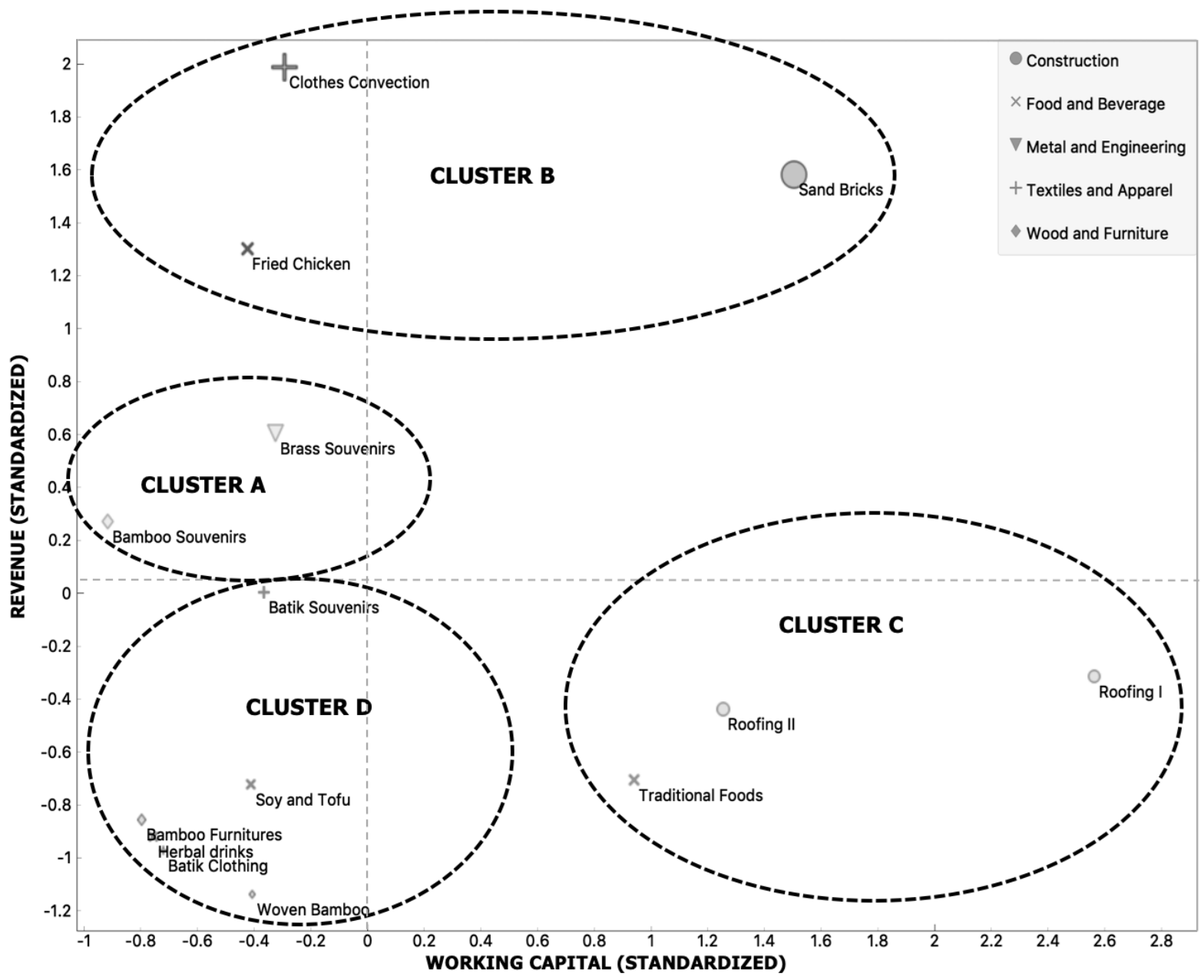

Fig. 3. Cluster Map of Industrial Centers

Table 3 . The average performance for each cluster in the taxonomy

\begin{tabular}{|c|c|c|c|c|c|}
\hline Industrial Centers & Cluster-ID & $\begin{array}{l}\text { Avg. Number } \\
\text { of Labors }\end{array}$ & $\begin{array}{c}\text { Avg. Revenue } \\
\text { (thousands IDR) }\end{array}$ & $\begin{array}{c}\text { Avg. Working } \\
\text { Capital (thousands } \\
\text { IDR) }\end{array}$ & $\begin{array}{c}\text { Avg. } \\
\text { Gross Margin }\end{array}$ \\
\hline $\begin{array}{l}\text { - Brass Souvenirs } \\
\text { - Bamboo Souvenirs }\end{array}$ & A & 2.7 & 23,255 & 1,581 & $413 \%$ \\
\hline $\begin{array}{l}\text { - Clothes Convection } \\
\text { - Fried Chicken } \\
\text { - Sand Bricks }\end{array}$ & B & 4.6 & 39,489 & 7,284 & $191 \%$ \\
\hline $\begin{array}{l}\text { - } \text { Roof I } \\
\text { - Roof II } \\
\text { - Traditional Food }\end{array}$ & $\mathrm{C}$ & 2.2 & 9,852 & 16,695 & $329 \%$ \\
\hline $\begin{array}{l}\text { - Batik Souvenirs } \\
\text { - Soy and Tofu } \\
\text { - Herbal Drinks } \\
\text { - Bamboo Furniture } \\
\text { - Batik Clothing } \\
\text { - Woven Bamboo }\end{array}$ & $\mathrm{D}$ & 1.4 & 3,491 & 1,872 & $154 \%$ \\
\hline
\end{tabular}




\subsection{Cluster C: High Investment, Low Revenue}

Cluster $\mathrm{C}$ is dominated by M-MSEs in the construction sector, such as the bricks and roof manufacturers. These enterprises are characterized by a high working capital but can only earn relatively low revenue per company compared to other clusters. These characteristics indicate that the enterprises in this cluster have a relatively small market. However, they also have a smaller number of competitors in their market due to the high capital requirement to enter the business.

Based on these characteristics, the companies could aim to increase their revenue by enlarging their market share from the current market. This could be achieved by strengthening their brands and trademarks to attract more customers from the market. This strategy requires enterprises to define their competitive advantage and point-of-difference compared to competitors' products. To help these enterprises, the authorities could provide a series of training in marketing strategy to enhance their position in the market.

However, from the interviews with the enterprise owners in Cluster C, we found that there are some barriers for these enterprises to develop a strong positioning in the market. One of the main barriers was that many of the products from these enterprises are unbranded and unregistered. Without a recognizable brand, their products would have difficulties to compete with competitors from outside. Most of the enterprises avoided the brand registration process because they felt that the process is complicated and expensive. Moreover, they are also afraid that by registering their brand to the authority, they will be charged with a higher tax and more complicated reports. Therefore, many of them chose to stay being informal and unregistered.

Even though the informal status of micro-business is typical in many developing countries, but it also reduces the chance for enterprises to access better opportunities in the future. The study from [20] found that informal MSEs tend to have slower growth compared to their formal counterparts. Therefore, the government could help to improve the M-MSEs in cluster C by aiming to simplify the brand registration procedure so that the enterprises can have a formal brand. This brand could help the M-MSEs to properly compete with other competitors in the market.

\subsection{Cluster D: Low Revenue, Low Margin}

The M-MSEs in Cluster D are characterized by a low revenue, low-profit margin, and low workforce. This cluster is mainly comprised of traditional businesses that produce natural herbs or traditional clothing. The enterprises are typically operated by one or two persons who often be family members. The purpose of the business is mainly to attain decent income and basic needs for living. According to [10], MSEs that do not expand in terms of employment are primarily survival types and actually can be extremely important in helping a large number of unfortunate people. Therefore, the government should take a role to enable these enterprises to sustain their business in the market to avoid massive poverty.

Unfortunately, the demand for traditional products in today's market is often limited, and the market size is typically sinking.
Besides, due to the limited skills, these enterprises also cannot aim to diversify their product range. Thus, in order to sustain the business, the enterprises in Cluster D should aim to maintain their current market by focusing on customer loyalty. To do so, enterprises should be able to provide exceptional service for their customers. It can be performed by developing a close relationship with the customers so that they can learn the needs and the values of their product from the customer perspective. Once the needs and the values are determined, the enterprises could slowly improve the profit margin by providing a higher quality service. In this way, they can sustain the business and continue to support the basic needs of the workers. In the literature, this strategy is also known as relationship marketing. [21] defines relationship marketing as an integrated effort to identify, maintain, and build up a network with individual customers through interactive contact over a long period. Relationship marketing was also proved to be a practical approach to win in a niche market [22]. The successful implementation of this strategy can foster a stronger bond with customers and improve their loyalty to the product [21].

\section{Concluding Remarks}

This study provides new insights into the characteristics of M-MSEs in a developing country, which is currently still underrepresented in the literature. Specifically, our study provides a taxonomy of Indonesian M-MSEs based on the empirical data of 735 enterprises in Yogyakarta. The study serves as a part of a larger effort to characterize the profile of MSEs in developing countries.

Data shows that the typical M-MSEs in Yogyakarta has a very small number of workers with 5.40 workers in average at the highest. The typical number of workers for small companies can be up to 20 (or 30) workers. The absence of enterprises that have around 10-20 workers gives a large gap to the medium enterprises. The local government can support by providing visions and missions for the enterprises to become medium and larger enterprises. One of the ways is by assessing whether the existing non-formal 'Industrial Center', that currently bonds multiple co-located micro-enterprises, can provide better opportunities and economies of scale when it is transform into a formal single medium enterprises.

Furthermore, based on cluster analysis, we also found that the characteristics of the M-MSEs in Yogyakarta can be grouped into four different clusters, namely Cluster A, B, C, and D. Cluster A represents a group of enterprises which yield high profit-margin but struggling to expand their business. Cluster B embodies a group of enterprises with a broad market but low profitability. Cluster $\mathrm{C}$ denotes a group of enterprises that operates with a high working capital but generate relatively low revenue. Lastly, Cluster D represents traditional enterprises with a low-profit margin and a niche market.

The study also implies that it is possible for a different sector to adopt different strategies instead of adhering to a single uniform strategy. Each cluster also found to have a unique characteristic that requires a unique strategy, such as adopting a lean philosophy to instituting relationship marketing, as shown in Table 4 . Those strategies are proposed in order to 
improve business sustainability of the M-MSEs so that they can grow into medium or large enterprises.

These conclusions, however, should be generalized with caution since the data used were mainly collected in Indonesia, particularly in Yogyakarta province. Consequently, the taxonomy may subject to regional-specific biases. Moreover, despite being useful for classification, the developed taxonomy may only embody a simplification of actual M-MSEs conditions. Future study may address this limitation by including samples from a wider geographic area to better represent the situation in Indonesia or in developing countries in general. In this sense, the current study can be positioned as a stepping stone toward a better understanding of the characteristics of M-MSEs in developing countries.

Table 4. Taxonomy of strategies for M-MSE

\begin{tabular}{|c|c|c|c|}
\hline Cluster-ID & Characteristics & Key Priority & Strategies \\
\hline A & $\begin{array}{l}\text { High margin, low working capital, } \\
\text { standard revenue }\end{array}$ & Capacity & $\begin{array}{l}\text { Increasing production capacity by procuring mechanical tools, } \\
\text { and establishing a vocational internship program }\end{array}$ \\
\hline B & $\begin{array}{l}\text { High revenue, high workforce, low } \\
\text { margin }\end{array}$ & Cost & Improving cost efficiency by adopting a lean philosophy \\
\hline $\mathrm{C}$ & $\begin{array}{l}\text { High investment, high margin, low } \\
\text { revenue. }\end{array}$ & Differentiation & Strengthen position in the market through branding strategy \\
\hline $\mathrm{D}$ & $\begin{array}{l}\text { Low revenue, low investment, low } \\
\text { margin }\end{array}$ & Delivery & $\begin{array}{l}\text { Building customer loyalty through relationship marketing and } \\
\text { commitment to product quality }\end{array}$ \\
\hline
\end{tabular}

Nonetheless, several managerial implications can also be concluded from this study. First, the authority may use this taxonomy as guidance to classify and characterize a similar group of M-MSEs in Yogyakarta. Based on this taxonomy, the government can deliver the required supports more efficiently instead of handling them one by one. Second, entrepreneurs can also use taxonomy as a benchmark to position their enterprise and adopt the recommended strategy to develop their business. For example, an enterprise with relatively high revenue and high workforce may adopt a lean philosophy to improve business profitability, while a traditional enterprise with a low margin and niche market may adopt relationship marketing to sustain their business in the market.

\section{Acknowledgments}

This study was partially funded by the Regional Office of Industry and Trade Department (Disperindag) of Sleman Regency, Indonesia.

\section{References}

1. BPS, Perkembangan data usaha mikro, kecil, menengah (UMKM) dan usaha besar (UB). 2017

2. BPS. Profil Industri Mikro dan Kecil. 2017.

3. T. Tambunan, Promoting small and medium enterprises with a clustering approach: A policy experience from Indonesia, J. Small Bus. Manag. 43 (2005) 138-154.

4. P. T. Ward and R. Duray, Manufacturing strategy in context: Environment, competitive strategy and manufacturing strategy, J. Oper. Manag. 18 (2000) 123-138.

5. BPS, Produk domestik regional bruto per kapita atas dasar harga berlaku menurut provinsi. 2018.

6. G. G. Dess and P. S. Davis, Porter's (1980) generic strategies as determinants of strategic group membership and organizational performance, Acad. Manag. 27 (1984) 467-488

7. S. Birley and P. Westhead, A taxonomy of business start-up reasons and their impact on firm growth and size, J. Bus. Ventur. 9 (1994) 7-31.

8. J. G. Miller and A. V. Roth, A taxonomy of manufacturing strategies, Manag. Scie. 40 (1994) 285-304.

9. B. S. Wibowo, A taxonomy of strategies for industry 4.0 implementation in indonesia, J. Ilmiah Bid. Tek. ANGKASA. 11 (2019) $1-8$.

10. D. C. Mead and C. Liedholm, The dynamics of micro and small enterprises in developing countries, World Dev. $26 \quad$ (1998) 61-74.

11. C. C. Sum, L. S. J. Kow, and C. S. Chen, A taxonomy of operations strategies of high performing small and medium enterprises in Singapore, Int. J. Oper. Prod. Manag. 24 (2004) 321-345.

12. G. P. McMahon, An empirical deriving development for manufacturing smes taxonomy australia's using data from business longitudinal survey, Small Bus. Econ. 17 (2001) 197-212.

13. J. Andersén, A resource-based taxonomy of manufacturing MSMEs, Int. J. Entrepren. Behav. Res. 18 (2012) 98-122.

14. C. Hironaka, M. A. Zariyawati, and F. Diana-Rose, A comparative study on development of small and medium enterprises (SMEs) in Japan and Malaysia, Saudi J. Bus. Manag. Studies 2 (2017) 357-374.

15. E. López-Ortega, D. Canales-Sanchez, T. Bautista-Godinez, and S. Macias-Herrera, Classification of micro, small and medium enterprises (M-SME) based on their available levels of knowledge, Technovation 47 (2015) 59-69.

16. J. Obi, et al., Contribution of small and medium enterprises to economic development: Evidence from a transiting economy, Data Brief 18 (2018) 835-839.

17. The World Bank. Indonesia Economi Quarterly: Towards inclusive growth 2018.

18. P. J. Rousseeuw, Silhouettes: A graphical aid to the interpretation and validation of cluster analysis, J. Comput. Appl. Math. 20 (1987) 53-65.

19. Y. C. Wong and K. Y. Wong., A lean manufacturing framework for the malaysian electrical and electronics industry, Proc. 3rd Int. Conf. Inf. Financ. Eng., 2011, pp. 30-34.

20. S. Nichter and L. Goldmark, Small firm growth in developing countries, World Dev. 37 (2009) 1453-1464.

21. D. Shani and S. Chalasani, Exploiting niches using relationship marketin. J. Consum. Mark. 9 (1992) 33-42.

22. E. Gummesson, Relationship marketing in the new economy, J. Relat. Mark. 1 (2002) 37-57. 